\title{
Labor market regimes and the effects of monetary policy
}

\author{
CEFOS Working Paper 2 \\ 2005 \\ Nicola Acocella \& Giovanni Di Bartolomeo \\ Department of Economics, University of Rome La Sapienza \\ Douglas A. Hibbs, Jr.* \\ CEFOS
}

\begin{abstract}
In this paper we use a standard multi-union, monopolistic competition model to investigate the qualitative and quantitative responses of inflation and unemployment to monetary policy activism under different institutional arrangements in the labor market, which are defined by the rigidity of nominal wages. We show that the effects of monetary policy on the real economy depend critically on the wage formation regime, and on the ways in which the restrictiveness of policy interacts with product price competition, with union centralization, and with the weight placed on real wage premiums as compared to unemployment in unions' optimal programs. Our interpretation of the results emphasizes how the posture of monetary policy toward inflation influences the strategic calculations that drive union wage setting behavior in different institutional settings.
\end{abstract}

*douglas@douglas-hibbs.com

Douglas.Hibbs@cefos.gu.se

\section{CEFŌS}

Centrum för forskning om offentlig sektor - Center for Public Sector Research www.cefos.gu.se 


\author{
CEFOS Working Paper 2 \\ Labor market regimes and the effects of monotary policy \\ (c) Nicola Acocella, Giovanni Di Bartolomeo \& Douglas A. Hibbs, Jr., 2005
}

ISSN: 1653-3895

\begin{tabular}{|c|c|}
\hline & \\
\hline & CEFOS \\
\hline Centrum för forskning om offentlig sektor & Götehora University \\
\hline $\begin{array}{r}10 x \\
\text { Box } 720\end{array}$ & P.O. Box 720 \\
\hline 40530 Göteborg & SE-405 30 Göteborg, Sweden \\
\hline office@cefos.gu.se & office@cefos.gu.se \\
\hline Tel. 031-773 4142 & Tel. +46 317734142 \\
\hline www.cefos.gu.se & www.cefos.gu.se \\
\hline
\end{tabular}




\title{
Labor market regimes and the effects of monetary policy ${ }^{\dagger}$
}

\author{
Nicola Acocella*, Giovanni Di Bartolomeo*, and Douglas A. Hibbs, Jr. ${ }^{* *}$ \\ forthcoming in Journal of Macreconomics
}

\begin{abstract}
In this paper we use a standard multi-union, monopolistic competition model to evaluate analytically and numerically the effects of monetary policy on inflation and unemployment under different institutional arrangements in the labor market that are defined by the rigidity of nominal wages. We show that the effects of monetary policy on the real economy depend critically on the wage formation regime, and on the ways in which the restrictiveness of policy interacts with product price competition, wage setting centralization and the utility weight unions place on real wage premiums as compared to unemployment. Our interpretation of the results emphasizes how the posture of monetary policy toward inflation influences the strategic calculations driving unions' wage setting behavior in different institutional environments.
\end{abstract}

JEL Classification: E52, E58, J51.

Keywords: Policy games, monetary policy neutrality, trade unions, monopolistic competition, labor markets.

\footnotetext{
* Department of Economics, University of Rome La Sapienza.

** Corresponding author: Douglas Hibbs, CEFOS, Göteborg University, Box 720, Göteborg 40530, Sweden; douglas@douglas-hibbs.com
}

\footnotetext{
${ }^{\dagger}$ Acocella and Di Bartolomeo gratefully acknowledge financial support from the University of Rome $L a$ Sapienza; Hibbs is grateful for support from the Göteborg University Donationsfonder. An earlier version of this paper appeared as Working Paper No 58 of the Public Economics Department, University of Rome La Sapienza.
} 


\section{Monetary policy, wage setting institutions and macroeconomic performance}

Monetary policy neutrality means that monetary instruments are unable to affect real variables, such as output and employment. ${ }^{1}$ The Barro-Gordon (1983) model and its many variants, inspired by the seminal paper of Kydland and Prescott (1977), are the main templates for modern analysis of monetary policy issues. In terms of the framework used in this paper and laid out below, the bare-bones Barro-Gordon setup corresponds to a game in which the central bank sets the money supply in order to minimize inflation and unemployment after unions set nominal wages so as to optimally trade off expected real wages and unemployment of their members. Although unions are Stackelberg leaders, the central bank's objectives and optimal policy reactions are common knowledge and union wage policies are conditioned on rational expectations of the money supply. Nominal wages are therefore adjusted to crowd-out the positive effects that monetary expansions otherwise would have on output and employment by moderating real wages. The result is a Stackelberg equilibrium characterized by monetary neutrality and excess inflation. ${ }^{2}$

A more favorable implication of this line of research is that a "conservative" central bank pursuing a stringent, non-accommodating policy is able to contain inflation without real costs in the form of systematically higher unemployment and depressed output - a view developed theoretically by Rogoff (1985) and supported to various degrees empirically by evidence in Grilli et al. (1991), Alesina and Summers (1993), Bleaney (1996) and Eijffinger et al. (1998)) and others, all of which took ratings of central bank independence as good proxies for policy conservatism. Non-neutrality was shown to arise, however, if wages only partially adjust to monetary changes because of the existence of multi-period overlapping contracts - as in Fischer (1977) - or because the policy authority has an information advantage over wage and price setters - as in Canzoneri (1985) - or because unions have a pure distaste for inflation as in Gylfason and Lindbeck (1994).

\footnotetext{
${ }^{1}$ The classical definition of monetary neutrality implies that autonomous changes in the money supply have no influence on the level of real output (Patinkin (1956)). In the policy games literature which came a generation later, money is typically endogenous. A definition better suited to modern frameworks of analysis would be that monetary policy is neutral (non-neutral) when equilibrium output and employment do not (do) depend on the preferences of the monetary policymaker (Acocella and Di Bartolomeo (2004)).

${ }^{2}$ Union power over nominal wage setting, however, might influence the monetary authority's objectives and constraints. Fischer and Summers (1989), for example, argued that other things being equal indexation lowers the cost of inflation, which by itself gives the authorities an incentive to pursue more inflationary policies. The implication is that union coordination effectively indexing wages would tend to increase inflation. On the other hand, Waller and VanHoose (1992) pointed out that indexation steepens the aggregate supply curve, reducing the output and employment gains from (unanticipated) inflation. The incentive to pursue an inflationary policy in the first instance is therefore diminished, implying that through this channel coordinated union action to index wages might reduce an inflation bias.
} 
More recent contributions to the policy game literature stress new channels of monetary nonneutrality that do not depend on sticky wages, information asymmetries and direct union aversion to inflation, but instead operate through the interaction of central bank policies with wage and price setting institutions. Theoretical demonstrations by Bratiosis and Martin (1999), Soskice and Iversen (2000), Coricelli et al. (2004, 2005), among others, implied that when there is a multiplicity of wage setting unions and product markets are monopolistically competitive, a Barro-Gordon framework may deliver policy non-neutrality. In particular, restrictive monetary policy rules that are internalized by wage and/or price setters can lead to favorable equilibrium outcomes for output and unemployment as well as inflation. Data reported in Soskice and Iversen (2000) and more extended empirical analyses by Hall (1994), Hall and Franzese (1998), Iversen (1999 ch.3), Cukierman and Lippi (1999) and Franzese (2001a, 2002 ch.4), which tested explicitly for the contingency of real monetary policy effects on the institutional framework of wage/price formation, yielded evidence broadly supporting this line of theory, although in his masterful review of these and related studies Franzese (2001b) conceded that "disagreement remains over the precise nature of these interactive effects” (p.457).

The aim of this paper is help clarify the sources and potential numerical magnitudes of institutionally contingent monetary non-neutrality. Specifically, we apply a workhorse multiunion, monopolistic competition model to pin down analytically and evaluate numerically the nominal and real macroeconomic effects of monetary policy in two distinct wage formation regimes: (i) "rigid" wage labor markets in which unions contract wages in advance for at least one period (commitment) and cannot alter their claims after the monetary authority acts, and (ii) "flexible" wage markets in which unions interact simultaneously with the central bank and may adjust wages freely in any period.

The remainder of the paper is organized as follows. In the next section we introduce the workhorse multi-union, monopolistic competition model. Solutions to the optimal programs of the central bank and labor unions are given in Section 3. In Section 4 we derive analytic solutions for wages, prices and unemployment levels in flexible and rigid wage labor markets, and we show the qualitative responses of these variables to variations in monetary policy conservativeness, centralization-coordination of wage setting, and price competition in product markets. In Section 5 we assign plausible ranges of numerical values to model parameters, and we calculate the quantitative effects of monetary policy conservativeness on macroeconomic outcomes under different assumptions about wage setting centralization, 
price competition, and the relative weight placed upon real wages vs. unemployment by unions operating in flexible and rigid wage institutional regimes. We give intuitive interpretations of the results, placing special emphasis on how the posture of policy in different institutional settings affects the strategic calculations of unions in setting nominal wage levels.

\section{The economic setup}

We use a simple, workhorse model $^{3}$ of an imperfectly competitive economy composed of several unions and monopolistically competitive firms. Several unions represent the entire labor force and exert monopoly power over nominal wage levels. ${ }^{4}$ We index unions by $i \in[1, n]$ and for simplicity assume they are equal in size, each representing a share of the labor force equal to $\sigma=1 / n$. An array of firms producing differentiated goods and services set product prices. One union represents the labor force and sets the nominal wage of workers in each firm. Firms associated with union $i$ are indexed by $i j$.

Firms maximize a one period profit function under demand and production technology constraints. Firm-level demand is

$$
Y_{i j}^{d}=\left(\frac{P_{i j}}{P}\right)^{-\eta} \frac{M}{P}
$$

where $Y_{i j}^{d}$ is demand for a firm's output, and $P_{i j}$ and $P$ are firm-product prices and the general price level, respectively. The latter is conveniently assumed to equal the geometric average of $P_{i j} . \eta \in(1, \infty)$ is the elasticity of product demand with respect to relative price. Firm-level demand is also affected by aggregate demand, which equals the aggregate real money supply $\frac{M}{P}$. The central bank controls aggregate demand perfectly by setting the money supply at any given price level.

Each firm uses a production technology defined by decreasing returns to labor inputs

$$
Y_{i j}=L_{i j}^{\alpha} \quad \alpha \in(0,1)
$$

\footnotetext{
${ }^{3}$ The Appendix gives fuller derivation of the economic setup which draws upon Bratiosis and Martin (1999), Soskice and Iversen (2000), and especially Coricelli et al. (2005) and Cukierman (2004).

${ }^{4}$ The model therefore is not applicable to economies in which wages are set mainly by individual bargains, as in the contemporary US, or to (notional) economies in which wages are mainly set by just one all-encompassing union. This point is made explicit in analyses of the model presented ahead.
} 
where $L_{i j}$ is the labor input of firm $i j$. Note that technological progress (secular productivity) is implicitly fixed at 1.0 .

Equations (1) and (2) imply that firm ij's conditions for profit maximization under monopolistic competition can be written as log-linear equations for relative product price and labor demand

$$
\begin{aligned}
& p_{i j}-p=\theta\left[(1-\alpha)(m-p)+\alpha\left(w_{i}-p\right)\right] \\
& l_{i j}^{d}=\theta\left[m-p-\eta\left(w_{i}-p\right)\right]
\end{aligned}
$$

where lower case variables denote logs of the corresponding upper case variables, $w_{i}$ is the $\log$ nominal wage level of workers in union $i$ and $\theta \in(0,1)=\frac{1}{\alpha+\eta(1-\alpha)}$.

As shown in the appendix, without loss of generality we set log labor supply parametrically to zero, from which it follows that the unemployment rate among union i's members implied by equation (4) is

$$
U_{i}=\theta\left[\eta\left(w_{i}-p\right)-(m-p)\right] .
$$

Taking averages of equations (3) and (4), one obtains (as shown in the Appendix) the following aggregate reduced forms for the log price level and the rate of unemployment in the macroeconomy:

$$
\begin{aligned}
& p=\alpha w+(1-\alpha) m \\
& U=w-m .
\end{aligned}
$$

By using equation (6) we can rewrite equation (5) as

$$
U_{i}=\theta\left[\eta w_{i}-\alpha(\eta-1) w\right]-m .
$$

Equation (8) implies that the unemployment rate of union i's members is positively related to union $i$ 's log nominal wage claims, $w_{i}$, and negatively related to the economy-wide, average log nominal wage level, $w$. The union-specific wage always dominates the economy-wide wage because $\eta>\alpha(\eta-1)$. Unemployment is also decreasing in the nominal money supply.

The economy-wide log nominal wage level is equal to $w=\sigma w_{i}+(1-\sigma) w_{-i}$, where recall $\sigma=\frac{1}{n}$ is the relative size of union i's membership (which is equivalent to the degree of 
centralization or coordination of nominal wage setting), and $w_{-i}$ is the average log nominal wage set by other unions. It follows that equation (8) can be expressed

$$
U_{i}=\theta\left\{(\eta-\alpha \sigma(\eta-1)) w_{i}-\alpha(1-\sigma)(\eta-1) w_{-i}\right\}-m .
$$

Equation (9) is the reduced form unemployment rate for union $i$. When setting the nominal wage, union $i$ faces two opposite effects. First, raising $w_{i}$ decreases employment demand for the union's members due to the higher labor costs imposed on the firm. Second, raising $w_{i}$ contributes to increasing the economy-wide wage, which by itself makes firm ij more competitive. The former effect naturally dominates the latter whenever wages are set by more than one union.

\section{Optimal policies}

\subsection{The central bank's problem}

We assume that the central bank sets the log money supply $m$ to maximize the following quadratic objective function, subject to (6) and (7):

$$
C B=-\frac{\beta}{2} \pi^{2}-\frac{U^{2}}{2}
$$

where $\pi=\left(p-p_{-1}\right)$ is the inflation rate and $\beta \in(0, \infty)$ defines the central bank's aversion to inflation (or deflation) relative to unemployment. For a one period optimal policy, the lagged price level, $p_{-1}$, is given parametrically, and so without loss of generality it can be set to zero, allowing us to treat current prices and inflation rates interchangeably; $\pi=p$.

Solving the central bank’s problem yields the wage-contingent optimal monetary policy rule

$$
m=-\phi w .
$$

The reaction parameter $\phi=\frac{\alpha(1-\alpha) \beta-1}{(1-\alpha)^{2} \beta+1}$ represents the central bank's willingness to accommodate nominal wage settlements, which we shall call monetary policy "conservativeness." When $\beta<\frac{1}{\alpha(1-\alpha)}$ and therefore $\phi<0$, wage increases are at least partly accommodated, and the central bank is "liberal” or "populist." As $\beta$ goes to its lower bound of zero, $\phi$ approaches the lower bound of its domain, -1 , and the central bank is ultra- 
liberal. Its objective function is targeted solely on minimizing the unemployment rate and monetary policy accommodates fully nominal wage increases. The reverse is true when $\beta>\frac{1}{\alpha(1-\alpha)}$. In this case $\phi>0$ and the central bank is conservative, setting the money supply so as to offset at least partly wage-induced increases to the price level. As the bank's inflation aversion parameter $\beta$ goes to its upper limit $\infty, \phi$ approaches its upper bound, $\alpha /(1-\alpha)$, and we observe the ultra-conservative central bank that aims only to minimize inflation. At $\beta=\frac{1}{\alpha(1-\alpha)}$, the reaction coefficient $\phi=0$. The central bank is "passive" and monetary policy is neither accommodating nor non-accommodating. ${ }^{5}$

\subsection{The labor unions' problem}

Each union seeks to maximize a linear-quadratic preference function, $T U_{i}$, with the membership's log real wage $\left(w_{i}-p\right)$ and unemployment rate $\left(U_{i}\right)$ as arguments:

$$
T U_{i}=\gamma\left(w_{i}-p\right)-\frac{U_{i}^{2}}{2} \quad i \in\{1,2, \ldots n\}
$$

where $\gamma>0$ is the relative utility weight of the log real wage premium. ${ }^{6}$

The first order condition for each union $i$ is

$$
\gamma\left(1-\frac{\partial p}{\partial w_{i}}\right)-U_{i} \frac{\partial U_{i}}{\partial w_{i}}=0
$$

where recall that the current period log price level, $p$, defines the inflation rate, $\pi$. The first order condition (13) represents the sensitivity of union wage policies to inflation and unemployment, respectively. As will become clear in the next section, after substitution for the endogenous variables $\pi$ and $U_{i}$ we obtain the corresponding optimality condition in terms of parameters and given variables.

\section{Labor market regimes}

\footnotetext{
${ }^{5}$ Hence, at a productivity parameter of $\alpha=2 / 3$ (the typical value for advanced economies), policy would be passive when the Central Bank's utility weight on inflation relative to unemployment, $\beta$, is equal to 4.5. Values greater or less than 4.5 therefore define what we call "conservative” and "liberal” policies, respectively. ${ }^{6}$ The real wage is the net-of-productivity premium because the production function in (2) excludes technological progress, and this implies that under perfect competition the equilibrium values of $w, p, m$ and $U$ are normalized to zero. These features of the model should be kept in mind when interpreting the settings of $\gamma$ and other parameters in section 5.1 .
} 


\subsection{Regimes and information}

Equilibrium outcomes of the game are obtained by solving equations (11) and (13) under the unions' information constraint. Different equilibrium concepts are associated with different information settings and associated specifications of expectations and, therefore, they vary by labor market regime. Following Ljungqvist and Sargent's (2000) discussion, a Stackelberg game implies that unions maximize their objectives by internalizing the central bank's reaction to their wage policies, and they cannot change nominal wages thereafter (because, for example, wages are bound by non-renegotiable contracts extending more that one period). Consequently, this regime is associated with pre-determined wages set one period in advance. By contrast, in a non-cooperative Nash gaming environment unions and the monetary authority interact simultaneously, taking realizations of $m$ and $w_{i}$, respectively, as given. What we designate a Nash game therefore implies flexible wages that can be adjusted every period along with the money supply. In both flexible and rigid wage labor markets monopolistic firms set prices after the realizations of wages and the money supply. The sequences of moves can be depicted

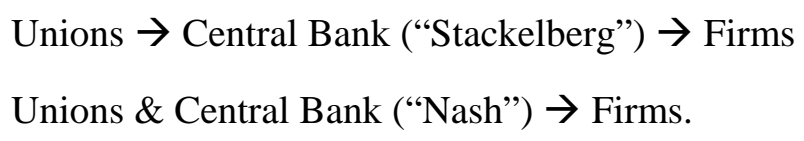

Both wage setting regimes are plausible. The Stackelberg leader-follower setup is consistent with the fact that in unionized economies wages are normally set one or more years in advance, whereas the central bank in principle can adjust monetary instruments with great frequency, giving it considerable flexibility vis-à-vis wage outcomes. On the other hand, monetary policy effects may be sluggish, which motivates the view that Nash solution concepts yield reasonable "one-shot" approximations to a repeated game between unions and the monetary authority. The most appropriate characterization of the labor market regime may therefore depend on the lag structure of policy effects, which for reasons outside the scope of this paper could well vary across time and space.

\subsection{Flexible labor markets}

In the Nash flexible wage case, each union finds the nominal wage that maximizes its objectives by differentiating the aggregate price (inflation) constraint in (6) and the unemployment function in (9) with respect to $w_{i}$, taking both the money supply, $m$, and the nominal wages of other unions, $w_{-i}$, as given, and substituting these derivatives into the 
optimality condition in (13). Each union i's optimality condition in flexible wage markets is then

$$
\gamma(1-\alpha \sigma)-U_{i} \cdot \theta(\eta-\alpha \sigma(\eta-1))=0
$$

which implies the wage setting function(s)

$$
w_{i}=\frac{\eta-\alpha(\eta-1)}{\eta-\alpha \sigma(\eta-1)} m+\frac{\alpha(1-\sigma)(\eta-1)}{\eta-\alpha \sigma(\eta-1)} w_{-i}+\gamma(1-\alpha \sigma)\left(\frac{\eta-\alpha(\eta-1)}{\eta-\alpha \sigma(\eta-1)}\right)^{2}>0
$$

for $i \in\{1,2, \ldots n\}$.

Union $i$ always reacts to monetary expansion by raising its wage claims less than proportionally, since the positive coefficient of $m$ in (15) is always less than one, except when all workers are represented by a single union $(\sigma=1)$, in which case the reaction coefficient on $m$ is unity. Moreover, union $i$ always responds to increases in the average wage of other unions by raising its nominal wage, no matter how conservative the central bank is.

The Nash equilibrium is found by solving the system of $n+1$ equations implied by equations (11) and (15). Imposing the symmetry condition $w=w_{i}=w_{-i}$ yields the economy-wide, equilibrium log nominal wage level as

$$
w=\left(\frac{1}{1+\phi}\right)\left(\frac{\eta-\alpha(\eta-1)}{\eta-\alpha \sigma(\eta-1)}\right)(1-\alpha \sigma) \gamma>0 .
$$

After substituting the optimal value of $w$ given by (16) and the optimal value of $m$ given by (11) into equations (6) and (7), equilibrium inflation and unemployment in the macroeconomy are

$$
\begin{aligned}
& \pi=\frac{(1-\alpha \sigma)(\eta-\alpha(\eta-1))(\alpha-\phi+\alpha \phi)}{(\eta-\alpha \sigma(\eta-1))(1+\phi)} \gamma \geq 0 \\
& U=\frac{(1-\alpha \sigma)(\eta-\alpha(\eta-1))}{\eta-\alpha \sigma(\eta-1)} \gamma>0 .
\end{aligned}
$$

Since the central bank's preferred inflation rate was normed to zero, equation (17) shows that an inflation bias exists, which represents an inefficient outcome of the non-cooperative Nash equilibrium that increases the central bank's disutility without affecting a union's felicity. 
The bias declines with increases to central bank "conservativeness," ${ }^{7}$ with increases to wage setting centralization, and with increases to product market competition:

$$
\begin{aligned}
& \frac{\partial \pi}{\partial \phi}=\frac{(\alpha(\eta-1)-\eta)(\alpha \sigma-1)}{(1+\phi)^{2}(\alpha \sigma(\eta-1)-\eta)} \gamma<0 \\
& \frac{\partial \pi}{\partial \sigma}=\frac{(\alpha-\phi(1-\alpha))(\alpha(\eta-1)-\eta)}{(1+\phi)(\eta+\alpha \sigma(1-\eta))^{2}} \alpha \gamma<0 \\
& \frac{\partial \pi}{\partial \eta}=\frac{(\alpha-\phi(1-\alpha))(1-\sigma)(\alpha \sigma-1)}{(1+\phi)(\alpha \eta(1-\eta)+\eta)^{2}} \alpha \gamma<0 .
\end{aligned}
$$

Since the conservativeness parameter, $\phi$, is the only term dependent on the central bank's preferences, it is clear from (18) that systematic monetary policy cannot affect the real economy, represented here by the unemployment rate $(U)$. Hence, in the flexible wage Nash regime we obtain the standard Barro-Gordon results of inflation bias and real-side policy neutrality, notwithstanding the complications to the economic environment introduced by the presence of a multiplicity of unions in the labor market and monopolistic price competition in product markets. However, unemployment decreases as both centralization (coordination) of wage setting and product market competition increase:

$$
\begin{aligned}
& \frac{\partial U}{\partial \sigma}=\frac{\alpha((\eta-1)-\eta)}{(\alpha \eta(1-\eta)+\eta)^{2}} \alpha \gamma<0 \\
& \frac{\partial U}{\partial \eta}=\frac{(1-\sigma)(\alpha \sigma-1)}{(\alpha \eta(1-\eta)+\eta)^{2}} \alpha \gamma<0 .
\end{aligned}
$$

At $\sigma=1$ or $\eta=\infty$, unemployment falls to its single union - competitive market minimum, $U=(1-\alpha) \gamma$, which for given productivity of labor, $\alpha$, increases linearly with the weight $\gamma$ attached to the real wage premium relative to unemployment. Note that $U=(1-\alpha) \gamma$ is not the "perfect competition" outcome. Unemployment goes to the competitive equilibrium $U=0$ only when unions with monopoly wage power place no weight on achieving a real wage above that warranted by productivity, that is, only when $\gamma=0$.

\subsection{Rigid labor markets}

\footnotetext{
${ }^{7}$ Note that the bias asymptotes to zero when the central bank becomes "ultra-conservative," that is, when the bank's utility weight on inflation approaches it upper limit $\beta=\infty$ and, therefore, the conservativeness policy parameter approaches its upper limit $\phi=\alpha /(1-\alpha)$.
} 
The rigid labor market or "Stackelberg" equilibrium is found in the usual way by solving the two-stage game by backward induction. ${ }^{8}$ In the second stage the central bank solves its problem taking nominal wages set by unions as given, which yields the optimal wagecontingent monetary policy rule of equation (11). In the first stage each union solves its problem by internalizing the central bank's reaction function (11), in the light of equations (6), (9) and the given wage claims of other unions. After substitution of the appropriate wage derivatives into (13), we derive the following realization of union i's optimal wage condition:

$$
\begin{aligned}
& \gamma\left(1-\frac{\partial \pi}{\partial w_{i}}\right)-\frac{\partial U_{i}}{\partial w_{i}}\left(\kappa_{1} w_{i}-\kappa_{2} w_{-i}\right)=0 \\
& \Rightarrow w_{i}=\frac{\kappa_{2}}{\kappa_{1}} w_{-i}+\frac{\gamma}{\kappa_{1}} \frac{\partial\left(w_{i}-p\right) / \partial w_{i}}{\partial U_{i} / \partial w_{i}}
\end{aligned} \quad \text { for } i \in\{1,2, \ldots n\}
$$

with $\kappa_{1}=(\eta-\alpha \sigma(\eta-1)) \theta+\sigma \phi, \quad \kappa_{2}=(\alpha(1-\sigma)(\eta-1)) \theta-(1-\sigma) \phi$.

Equation (19) represents a system of $n$ equations. By imposing the symmetry condition $w=w_{i}=w_{-i}$ and solving, we obtain the economy-wide equilibrium log nominal wage as

$$
w=\frac{(1-(\alpha-\phi+\alpha \phi) \sigma)(\alpha+(1-\alpha) \eta)}{(\eta(1-\sigma(\alpha-\phi+\alpha \phi))+\alpha \sigma(1+\phi))(1+\phi)} \gamma>0 .
$$

Inflation and unemployment in the macroeconomy may be derived directly from equation (20) given equations (6), (7), and (11). We have

$$
\begin{aligned}
& \pi=\frac{(1-(\alpha-\phi+\alpha \phi) \sigma)(\alpha-\phi+\alpha \phi)(\alpha+(1-\alpha) \eta)}{(\eta(1-\sigma(\alpha-\phi+\alpha \phi))+\alpha \sigma(1+\phi))(1+\phi)} \gamma \geq 0 \\
& U=\frac{(1-(\alpha-\phi+\alpha \phi) \sigma)(\alpha+(1-\alpha) \eta)}{\eta(1-(\alpha-\phi+\alpha \phi) \sigma)+\alpha \sigma(1+\phi)} \gamma>0 .
\end{aligned}
$$

As in the flexible wage regime, equation (21) shows that in rigid wage labor markets optimal policy again creates an inflation bias that declines with central bank conservativeness, wage setting centralization, and product market competition:

$$
\frac{\partial \pi}{\partial \phi}=\frac{(\alpha(\eta-1)-\eta)\left\{\begin{array}{l}
n(\sigma(\alpha+\phi(\alpha-1))-1)^{2}+ \\
\alpha \sigma(1+\phi) \cdot(2 \sigma(\phi(1-\alpha)-\alpha)-\phi(1-\alpha)+1+\alpha)
\end{array}\right\}}{(1+\phi)^{2}\{\alpha \sigma(1+\phi)+\eta(1-\sigma(\alpha-\phi(1-\alpha)))\}^{2}} \gamma<0
$$

\footnotetext{
${ }^{8}$ Strictly speaking we have a three stage game with firms moving last to set fully flexible prices that are perfectly anticipated and internalized by unions and the monetary authority. Our focus is on union-central bank interactions and nothing is lost by abstracting from the price setting stage.
} 


$$
\begin{aligned}
& \frac{\partial \pi}{\partial \sigma}=\frac{(\alpha-\phi(1-\alpha))(\alpha(\eta-1)-\eta)}{\{\alpha \sigma(1+\phi)+\eta(1+\sigma \phi(1-\alpha)-\alpha \sigma)\}^{2}} \alpha \gamma<0 \\
& \frac{\partial \pi}{\partial \eta}=\frac{(\alpha-\phi(1-\alpha))(1-\sigma)(\alpha \sigma-1+\sigma \phi(\alpha-1))}{(1+\phi)\{\alpha \sigma(1+\phi)+\eta(1+\sigma \phi(1-\alpha)-\alpha \sigma)\}^{2}} \alpha \gamma<0 .
\end{aligned}
$$

Equation (21) also implies that the inflation bias again goes to zero when the central bank becomes ultra-conservative, that is as $\beta \rightarrow \infty$ and $\phi \rightarrow \alpha /(1-\alpha)$.

Unlike the situation in the flexible wage regime, however, equation (22) shows that unemployment in the rigid wage regime is a negative function of central bank conservativeness $\phi$

$$
\frac{\partial U}{\partial \phi}==\frac{(1-\sigma) \sigma(\alpha(\eta-1)-\eta)}{\{\alpha \sigma(1+\phi)+\eta(1-\sigma \phi(1-\alpha)-\alpha \sigma)\}^{2}} \alpha \gamma<0 .^{9}
$$

Hence, monetary policy is non-neutral, and conservative monetary policy is able to achieve both lower inflation and lower unemployment when wages are pre-committed vis-à-vis monetary policy. Unemployment also falls, as in the flexible wage case, with increases to union centralization and product price competition:

$$
\begin{aligned}
& \frac{\partial U}{\partial \sigma}=\frac{(1+\phi) \alpha((\eta-1)-\eta)}{\{\sigma(1+\phi)+\eta(1-\sigma(\alpha-\phi(1-\alpha)))\}^{2}} \alpha \gamma<0 \\
& \frac{\partial U}{\partial \eta}=\frac{(1-\sigma) \sigma(\alpha-\phi(1-\alpha)-1)}{\{\alpha \sigma(1+\phi)+\eta(1-\sigma(\alpha-\phi(1-\alpha)))\}^{2}} \alpha \gamma<0 .
\end{aligned}
$$

\section{Summary and interpretation of results}

The general pattern of macroeconomic outcomes associated with flexible and rigid wage labor market regimes, along with those associated with the limiting cases of a completely centralized wage setting and perfectly competitive product markets, are summarized in Table 1.

\footnotetext{
${ }^{9}$ Note however that this effect goes to zero as wage setting centralization $\sigma$ goes to 1 (all wages are set by a single union) or to 0 (all wages are set individually). We discuss this below.
} 
Table 1. Parameter effects on inflation and unemployment in various settings ${ }^{*}$

\begin{tabular}{|c|c|c|c|}
\hline (a) & (b) & (c) & (d) \\
\hline $\begin{array}{c}\text { Flexible wage } \\
\text { regime } \\
\text { ("Nash") }\end{array}$ & $\begin{array}{l}\text { Rigid wage } \\
\text { regime } \\
\text { ("Stackelberg") }\end{array}$ & $\begin{array}{l}\text { Single union } \\
\qquad(\sigma=1)\end{array}$ & $\begin{array}{c}\text { Perfect } \\
\text { competition } \\
(\eta=\infty)\end{array}$ \\
\hline$U$ & $U$ & $U$ & $\pi$ \\
\hline
\end{tabular}

\section{Parameter effects}

Monetary policy conservativeness, $\phi$

Product market price competition, $\eta$

Union wage centralization, $\sigma$

Union real wage weight, $\gamma$

$\begin{array}{cccccccc}- & N & - & - & - & N & - & N \\ - & - & - & - & N & N & & \\ - & - & - & - & & & N & N \\ + & + & + & + & + & + & + & +\end{array}$

*The table reports the sign of the effect of increases in the parameters in the first column on inflation $(\pi)$ and unemployment $(U) . N$ indicates no effects. The outcomes associated with cases (c) and (d) are independent of the wage regimes.

The first row of Table 1 indicates that the degree of central bank conservativeness always affects inflation, but has capacity to affect unemployment (the real economy) only if a multiplicity of uncoordinated unions pre-commit wages in an economy with less than perfectly competitive product markets. The other rows show the signs of the effects of product market competition, wage setting centralization, and the weight unions place upon real wage premiums as compared to unemployment - none of which depend on the operative wage regime. Rows 2 and 3 imply that increasing either product market competition or wage setting coordination reduces both inflation and unemployment in the both flexible and rigid wage regimes. Note that the size of unions (the degree of centralization of wage setting) affects macroeconomic outcomes only if firms exert market power over product prices, that is when $\eta<\infty$. Similarly, the degree of market competition affects outcomes only if there is a multiplicity of unions (less than full coordination of wage setting), $\sigma<1$. Absent either a multiplicity of unions or imperfect product competition, monetary policy is neutral.

Row 4 reflects the usual consequences of union emphasis on real wages under a diminishing returns production technology and a downward sloping demand for labor. The greater the weight placed on the (net of productivity) real wage relative to unemployment, the higher are both unemployment and inflation in all types of labor and product markets. The overall 
pattern of results delivers quite standard inferences: A low unemployment and low inflation macroeconomy are promoted by conservative, anti-inflation central bankers, highly competitive product markets, and highly coordinated unions that place relatively small weight on real wage premiums as compared to unemployment.

The more illuminating issue of whether rigid or flexible wage labor markets deliver "better" macroeconomic performance depends on the central bank's inflation aversion. It is clear from previous analyses that comparative statics of the parametric results are cumbersome, and so the topic is more informatively addressed by graphical analysis of simulated outcomes. In order to evaluate the quantitative impact of monetary policy under different wage formation regimes we need to pin down values of some parameters, and to limit the range of others.

\subsection{Baseline parameter settings}

Labor's share of income in developed economies generally lies in the vicinity of two-thirds of GDP, so we set the productivity parameter to $\alpha=2 / 3$ in all simulation experiments. ${ }^{10}$ Price elasticities of demand, even for sectors producing relatively elastic goods and services, are in general unlikely to exceed 1.5, and only infrequently to exceed 2.0. We use a baseline setting for $\eta=1.3$ in some simulations, and investigate the effects of values spanning 1.1 to 2.0 in another. $^{11}$

Wage formation in developed European market economies is typically dominated by 2 to 3 large unions, ${ }^{12}$ which implies a representative value of $\sigma=0.4$ for the wage setting centralization parameter. ${ }^{13}$ A labor force organized by one all-encompassing union (or a degree of inter-union coordination that amounts to the same thing) has never existed in a democratic capitalist economy, and likely never will. Even during the heydays of "solidarity" bargaining in Scandinavia there were two principal peak unions whose wage policies were only partly synchronized. In simulations investigating the quantitative impact of wage centralization we analyze values of $\sigma$ spanning 0.20 to 0.8 ; the highest setting is taken to

\footnotetext{
${ }^{10}$ Note however that $\alpha$ can be equated to labor's share only under perfect competition. When firms have market power, the share tends to understate the output elasticity of labor input. For our purposes the baseline value adopted suffices however.

${ }^{11}$ As shown in the Appendix (and as in any case is well known), the optimal markup of price over marginal cost among firms with market power is $\left(1-\frac{1}{\eta}\right)^{-1}$. Calibrated analyses by Gordi (1995) produced markups in the range 2.2 to 4.5 , which correspond to values of $\eta$ spanning 1.3 to 1.8 , which are covered by our settings.

${ }^{12}$ Golden, Lange and Wallerstein (2002).

${ }^{13}$ However see the remarks ahead about effective centralization under a monetary union.
} 
represent the effective degree of wage setting coordination in a labor market with two, less than fully coordinated peak unions.

Recent econometric estimates of average equilibrium unemployment rates in European economies under the policies, labor market institutions and product market conditions prevailing in the late 1990's fall in a fairly broad range - between $5 \%$ and $8.5 \% .{ }^{14}$ For that range of empirical estimates, calculations based on our parameterizations of equilibrium unemployment imply that the weight placed by unions on the net-of-productivity real wage premium likely falls in the interval $\gamma \in[0.1,0.15]$, given a labor input elasticity in the vicinity of $\alpha=2 / 3$. We study the effects of a somewhat broader range $\gamma \in[0.075,0.175]$, but we use $\gamma=0.125$ (that is, a targeted real wage premium of $12.5 \%$ ) as the baseline setting in simulations fixing the value of this parameter.

Central bank behavior, on the other hand, appears empirically to have spanned far more of its theoretical domain than other variable parameters in the model. At various times during preEMU period in Europe, the monetary policies of Banca d'Italia probably came closer than the policies of other monetary authorities in developed economies to ultra-liberal, near full accommodation of wage inflation, represented in the model by $\beta \approx 0$ and $\phi \approx-1 .{ }^{15}$ At the opposite end of the spectrum, the Deutsche Bundesbank generally pursued very restrictive policies, as has the European Central Bank since the monetary union. In these cases, the posture of policies was probably not been too far from the ultra-conservative limit $\beta=\infty$, $\phi=\alpha /(1-\alpha)$.

\subsection{Model simulations}

Figure 1 shows graphs of inflation and unemployment outcomes in flexible and rigid wage labor market regimes in relation to the full range of monetary policy conservativeness when other parameters are set to baseline values. The model simulations indicate that moderately conservative monetary policies yield low single-digit inflation rates and unemployment rates in the $6-8 \%$ range, as opposed low double-digit inflation and unemployment rates of $8-10 \%$ under moderately liberal monetary policies. The simulations deliver quantitative results broadly consistent with experience in EU economies, which implies that the baseline parameter settings are credible.

\footnotetext{
${ }^{14}$ See, for example, Douven (2002) and Logeay and Tober (2003)

${ }^{15}$ The liberal limits proper are ruled out because at $\beta=0, \phi=-1$ and inflation goes to infinity. See equations (17) and (21).
} 


\section{Figure 1. Inflation and Unemployment in Flexible and Rigid Wage Regimes as Monetary Policy Conservativeness Increases *}

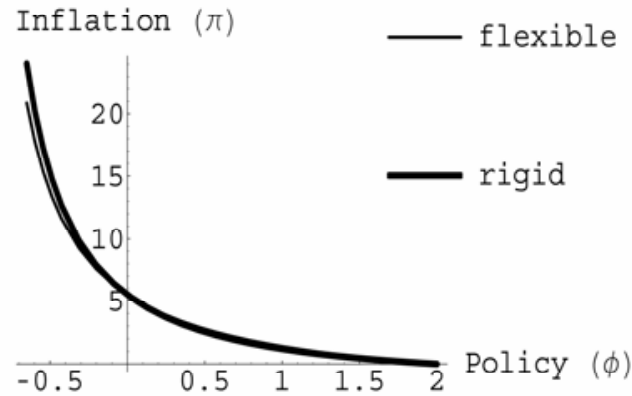

(1a)

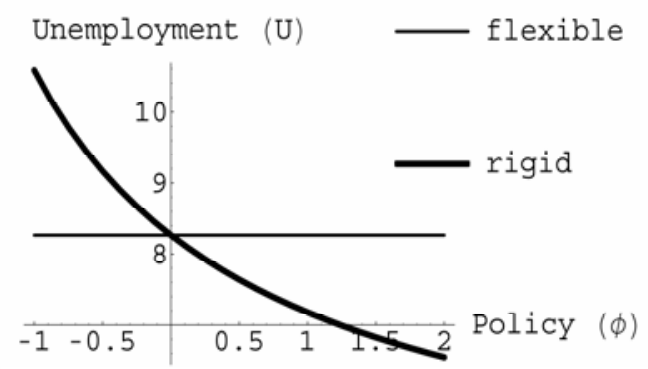

(1b)

*Percentage inflation rates and percentage point rates of unemployment are log approximations and were generated by parameter settings $\alpha=2 / 3, \gamma=0.125, \sigma=0.4$ and $\eta=1.3$ as $\phi$ goes from its lower bound, -1 , to its upper limit, $\alpha /(1-\alpha)=2$. The ultra-liberal lower bound of conservativeness is truncated in 1 (a) because $\pi \rightarrow \infty$ as $\phi \rightarrow-1$.

We know from equations (17) and (21) that in both flexible and rigid wage regimes inflation declines with central bank conservativeness $\phi$. Analysis of those equations shows that when monetary policy is liberal or "populist" $(\phi<0)$, inflation is lower in flexible wage than in a rigid wage regimes. However, if policy is conservative $(\phi>0)$, the opposite is true and inflation is lower in rigid regimes than in flexible ones. But the quantitative differences are small to vanishing for plausible parameter settings, and they cannot be detected at all from the inflation graph lines in Figure 1(a) where policy is in the moderately liberal to ultraconservative range $(\phi>-.5)$. When policy is passive and therefore does not respond to nominal wage developments $(\phi=0)$, inflation naturally converges across wage formation regimes. Inflation outcomes across regimes also converge to zero when policy approaches the ultra-conservative maximum $\phi=\alpha /(1-\alpha)$.

Equation (18) showed that unemployment is unresponsive to systematic monetary policy in flexible wage regimes, whereas eq. (22) implies that in rigid wage regimes unemployment is a decreasing convex function of central bank conservativeness. Analysis readily demonstrates that if monetary policy is liberal, unemployment equilibriums are always higher in Stackelberg, rigid wage environments than in Nash, flexible wage ones. When monetary is 
conservative, the pattern is reversed and rigid wage systems yield superior unemployment (employment) outcomes. Moreover, by contrast to the inflation outcomes, the differences become large as monetary policy deviates significantly in either a liberal or conservative direction from the passive policy posture of $\phi=0$. Figure 1(b) depicts the pattern of results scaled to baseline values of model parameters.

The explanations for the patterns in Figure 1 can be traced to the monetary transmission mechanisms and associated incentives of unions to pursue ambitious wage policies in different institutional settings. Under monopolistic price competition and a multiplicity of atomistic unions, the contribution of union-specific nominal wages, $w_{i}$, to the general price level, $p$, is small by comparison to its impact on firm-specific product prices, $p_{i j}$. Each uncoordinated union rationally exploits the wedge between log real consumption wage received by its members, $\left(w_{i}-p\right)$, and the log real product wage faced by individual firms, $\left(w_{i}-p_{i j}\right)$, by increasing nominal wages in order to achieve higher real wages, discounting the impact of its behavior on the general price level and, therefore, on the real wages of other unions. Since all unions behave in like fashion, the ensuing increase to the general price level (eq. 6) reduces aggregate demand via the negative effect on real money balances (eqs. 1, A.11), which in turn pushes up unemployment (eq. 5).

In a flexible wage Nash regime, unions interact simultaneously with the central bank, and take the money supply, along with the wages of other unions, as given. Union nominal wage policies are therefore unaffected by systematic monetary policy reactions (eq. 15). Even a Draconian anti-inflation policy is unable to overcome any of the unemployment costs created by the wage behavior of uncoordinated individual trade unions (eq. 18) pursuing best-reply Nash strategies. By contrast in a rigid wage Stackelberg regime, unions internalize reactions of the central bank (eq. 11), and this affects their strategic calculations. The unemployment effects of union wage policies are either aggravated or mitigated, depending on the posture of policy.

Each union in a rigid wage labor market takes account of the fact that a liberal central bank reacts to nominal wage rises with an accommodating expansion of the money supply $(\phi<0)$ that yields higher inflation for given a wage increase (eq. 21). Unions internalize the anticipated higher price level, which raises the optimal nominal wage consistent with their real wage-unemployment objectives (eqs. 13, 19-20), thereby magnifying both the inflation bias and aggregate unemployment costs associated with decentralized wage formation (eqs. 
21-22). Under liberal monetary policies both economy-wide inflation (eq. 6) and unemployment (eq. 7) are therefore higher when nominal wages are rigid as compared to being flexible, as depicted in Figure 1.

Analogously, unions in rigid wage regimes internalize the fact that a conservative central bank reacts to nominal wage increases with a non-accommodating contraction of the money supply $(\phi>0)$. Monetary contractions negatively affect inflation (the general price level) and this raises the real wage premium and the ensuing unemployment induced by a given increase to the nominal wage. As a result the real wage satisfying every union's optimality condition can be achieved with smaller nominal wage increases (eq. 19). Hence by assuring some degree of price stability (a low inflation bias), the central bank partly alleviates the negative employment externality arising from decentralized wage formation. Consequently, both inflation and unemployment are lower than when wages are set independently of anticipated policy reactions.

Intuition is deepened by evaluation of each union's optimal condition for nominal wage setting given by equation (13). The first order condition $\gamma\left(1-\frac{\partial p}{\partial w_{i}}\right)-U_{i} \frac{\partial U_{i}}{\partial w_{i}}=0$ implies that unemployment of union i's members is proportional to the implicit marginal rate of substitution between the real wage premium and unemployment embedded in the union's preference function: $U_{i} \Rightarrow \gamma\left(1-\frac{\partial p}{\partial w_{i}}\right) / \frac{\partial U_{i}}{\partial w_{i}}$. In flexible wage regimes, optimal wage setting and, consequently, unemployment among union i's members is policy-independent (independent of $\phi$ )

$$
\left.\frac{\gamma\left(1-\partial p / \partial w_{i}\right)}{\partial U_{i} / \partial w_{i}}\right|_{w_{i} \text { flex }}=\frac{(1-\alpha \sigma) \gamma}{(\eta-\alpha \sigma(\eta-1)) /(\alpha+\eta(1-\alpha))}
$$

However in rigid wage regimes wage setting it is policy-dependent

$$
\left.\frac{\gamma\left(1-\partial p / \partial w_{i}\right)}{\partial U_{i} / \partial w_{i}}\right|_{w_{i} \text { rigid }}=\frac{(1-\alpha \sigma+\sigma \phi(1-\alpha)) \gamma}{((\eta-\alpha \sigma(\eta-1)) /(\alpha+\eta(1-\alpha)))+\sigma \phi}
$$

and so the unemployment rate each union falls as the restrictiveness of monetary policy increases $\frac{\left.\partial \frac{\gamma\left(1-\partial p / \partial w_{i}\right)}{\partial U_{i} / \partial w_{i}}\right|_{w_{i} \text { rigid }}}{\partial \phi}<0$. Moreover, in a rigid wage labor market each union's 
marginal rate of substitution is (1) greater than its marginal rate of substitution would be in a flexible wage market when $\phi<0$, (2) equal to it when $\phi=0$, and (3) less than its marginal rate of substitution would be in a flexible wage market when $\phi>0$. Since all unions behave symmetrically, we obtain the macroeconomic outcomes associated with rigid and flexible wage regimes described above and graphed in Figure 1.

Figures 2-4 graph unemployment outcomes in rigid and flexible wage regimes in relation to the full range of central bank conservativeness and constrained variation in the remaining model parameters $\sigma, \eta$ and $\gamma$. We focus on unemployment outcomes alone because the responses of inflation to plausible variations of all model parameters do not yield sizeable differences across wage setting regimes. As in the baseline results graphed in Figure 1, it is on the real side of the economy - represented in our model by the unemployment rate where big differences in monetary effects emerge in rigid as compared to flexible wage labor markets.

The results graphed in Figure 1(b), as well as the results of the previous comparative statics, implied that the influence of monetary policy on relative unemployment outcomes originates with the way that systematic central bank reactions to wage changes affect unions' strategic calculations in rigid wage labor markets. It is clear from Figures 2-4 that under almost all reasonable variations of wage setting centralization, product price competition, and union real wage orientation, the effects activist monetary policies on unemployment performance in rigid wage regimes are several percentage points in magnitude, even when the monetary policy reaction function $m=-\phi w$ is evaluated within a truncated range that likely corresponds to nearly all empirical experience, $\phi \in[-0.5,1.5] .^{16}$

Figure 2 shows the response of unemployment rates to monetary policy as union centralization varies over empirically relevant values. When unions are big and therefore set wages for a large fraction of the labor force, they understand that their wage policies have great impact on the general price level and, consequently, that the wedge between product real wages and consumption real wages opened up by nominal wage increases is correspondingly small. Hence, in both rigid and flexible wage environments, large unions correctly perceive that the real wage return to aggressive nominal wage policies is comparatively weak, especially in relation to the utility cost of wage-induced increases to

\footnotetext{
${ }^{16}$ At $\alpha=2 / 3$, the corresponding range of the central bank's utility weight on inflation as compared to unemployment is $\beta \in[1.8,45]$.
} 
unemployment among union members (eqs. 8-9). Union size (centralization or coordination of wage setting) therefore tempers optimal wage aspirations, yielding lower firm-level price rises and lower union-level unemployment as centralization of wage setting increases - the right-sides of equations (24) and (25) both decline as $\sigma$ rises. Consequently, as shown analytically in section 4 by the comparative statics for equations (17)-(18) and (21)-(22), economy-wide rates of inflation and unemployment fall in both wage setting regimes with greater centralization of nominal wage formation.

In rigid wage systems, however, the effects of union centralization interact with the restrictiveness of monetary policy, and this can create large differences in unemployment outcomes across wage setting regimes. At any given degree of centralization, the internalization of liberal policies by unions that pre-commit nominal wages, rationally leads to more aggressive wage policies as monetary policy becomes more accommodating, and this yields rates of inflation and unemployment that always exceed the corresponding rates in flexible wage regimes where the money supply is taken as given. The otherwise beneficial effects of wage setting centralization are eroded completely as policy approaches the ultraliberal limit $\phi=-1$, which is depicted by the converging graph lines in Figure 2 for unemployment outcomes in rigid wage labor markets at large negative values of $\phi$.

\section{Figure 2. The Effects of Monetary Policy Conservativeness on Unemployment by Variation in Centralization of Wage Setting}

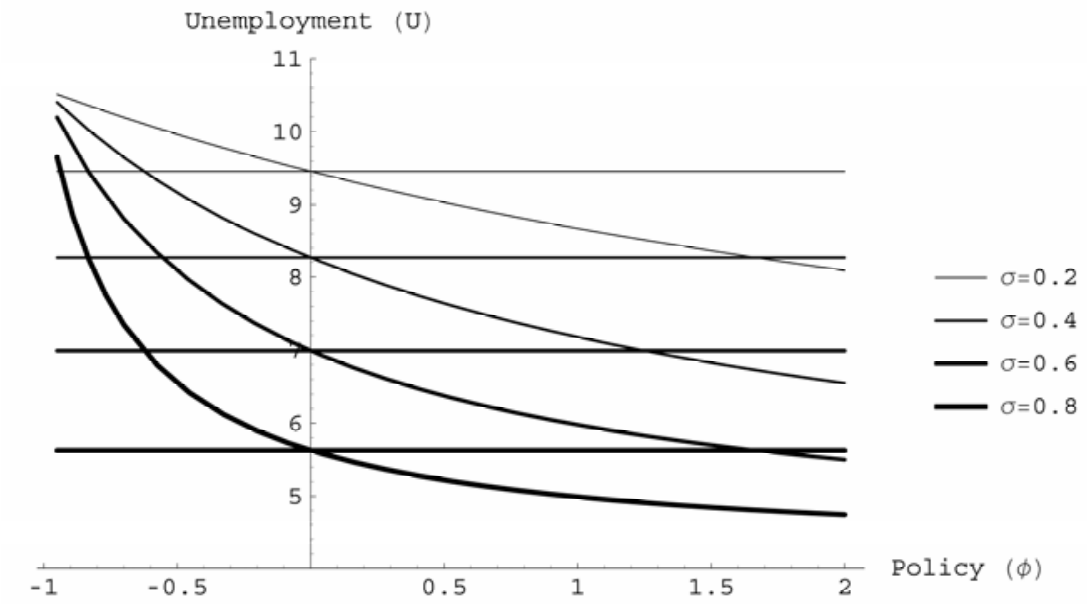

\footnotetext{
*Percentage point rates of unemployment are log approximations and were generated by parameter settings $\alpha=2 / 3, \gamma=0.125$ and $\eta=1.3$ as $\phi$ goes from its lower bound, -1 , to its upper limit, $\alpha /(1-\alpha)=2$ for various degrees of wage setting centralization, $\sigma$. Rigid wage outcomes are depicted by the convex graph lines; flexible wage outcomes by the parallel lines.
} 
The reverse is true in rigid wage labor markets when policy is conservative and the central bank contracts the money supply in proportion to nominal wage increases. The bigger (or more coordinated) are unions, the greater is the internalization of anti-inflation monetary policies, and the lower are rates of unemployment (and inflation) by comparison to outcomes in flexible wage labor markets, as Figure 2 shows. However, central bank conservativeness is only a second best way of solving coordination problems among atomistic unions. The lowest rate of unemployment attainable by an ultra-conservative central bank operating in a rigid wage regime is $U=\frac{\eta(1-\alpha)+\alpha}{\eta(1-\alpha)+\alpha \sigma}(1-\alpha) \gamma$, which exceeds the single union-perfect competition minimum $U=(1-\alpha) \gamma$ by a factor that declines as wage setting becomes more centralized. At the limit, when all wages are set by one all-encompassing union - that is, as $\sigma \rightarrow 1$ or, equivalently, as the wage behavior of notionally independent unions becomes perfectly coordinated which amounts to the same thing - monetary policy no longer affects union wage policies because a single union fully internalizes on its own the macroeconomic consequences of its nominal wage behavior. Consequently monetary policy is neutral. ${ }^{17}$ (See row 1, column c of Table 1) However, as mentioned before, complete centralization of wage setting has never been observed in a market economy.

Note that the establishment of a monetary union - notably the EMU - effectively decreases wage setting centralization because the nominal wage rises obtained by even the largest national unions have comparatively small effect on the union-wide wage and price levels and, consequently, have correspondingly small influence on union-wide monetary policy. Ceteris paribus, monetary union therefore tends to raise equilibrium unemployment, ${ }^{18}$ unless there are offsetting changes elsewhere in the macro political economy. One offsetting change could be - and, in fact, has been in the case of the EMU - a shift to more conservative monetary policy (bigger $\phi$ ) facing unions of the typical member nation. Another is a parallel increase

\footnotetext{
${ }^{17}$ Another way to think about this, which originates with an insight of an anonymous reviewer, is that the presence of a multiplicity (" $n$ ”) of uncoordinated unions - defined by $\sigma=\frac{1}{n}<1$ - amounts also to saying that each union behaves as if it were the only Stackelberg leader. Alternatively, if each union were to internalize the behavior of the others in its wage setting behavior, policy would again be neutral. As noted in the main text, such behavior defines perfect wage coordination and is functionally equivalent to $\sigma=1(n=1)$. Note too that policy becomes neutral as $\sigma \rightarrow 0(n \rightarrow L \rightarrow \infty)$, that is, when the wage setting is completely atomized so that the impact of any individual wage on economy-wide aggregates is negligible.

${ }^{18}$ This potential effect of monetary union appears to have been identified first by Hall (1994), and was subsequently discussed by Hall and Franzese (1998), Soskice and Iversen (1998) and Cukierman and Lippi (2001).
} 
in market competition (bigger $\eta$ ), which also has been an integral feature of the deepening of the European Community project. ${ }^{19}$

Figure 3 shows that the direct impact of product market price competition on unemployment $^{20}$ and on the efficacy of restrictive policy in driving down unemployment are very big at plausible settings of model parameters. In rigid wage labor markets, where monetary policy has capacity to influence union wage claims, unemployment is again exacerbated if policy is "populist" and is improved if policy is conservative. However note that policy exerts more potent effects on unemployment as product markets become less competitive - the convex graph lines get steeper as $\eta$ decreases. The reason is that relatively small values of $\eta$ (less market competition) yield relatively high monopoly rents to firms and, therefore, higher wages to unionized workers, which in turn raises unemployment. ${ }^{21}$

\section{Figure 3. The Effects of Monetary Policy Conservativeness on Unemployment by Variation in Product Market Competition*}

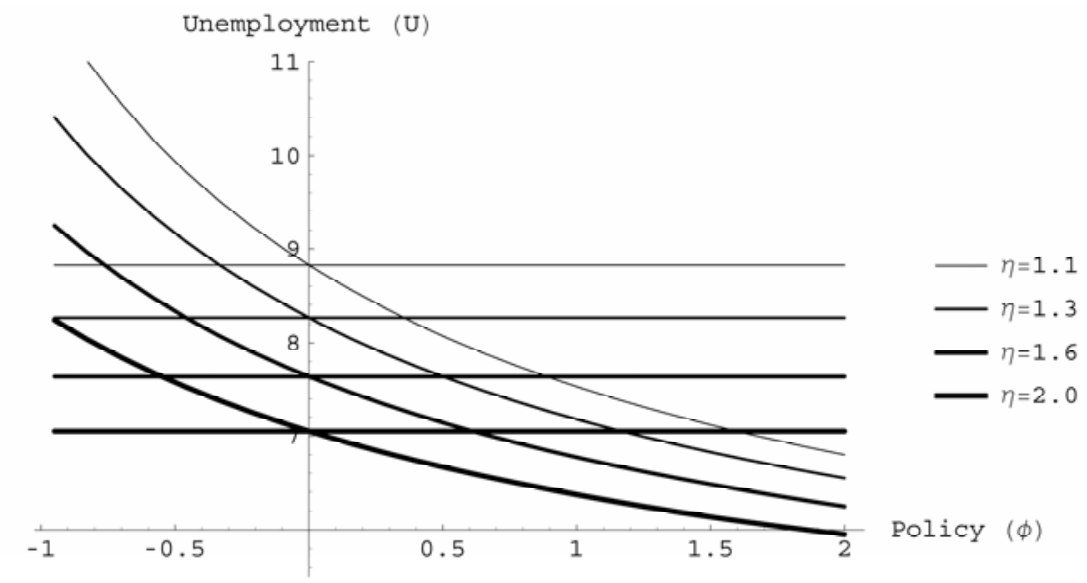

*Percentage point rates of unemployment are log approximations and were generated by parameter settings $\alpha=2 / 3, \gamma=0.125$ and $\sigma=0.4$ as $\phi$ goes from its lower bound, -1 , to its upper limit, $\alpha /(1-\alpha)=2$ for various elasticities of price competition, $\eta$. Rigid wage outcomes are depicted by the convex graph lines; flexible wage outcomes by the parallel lines.

Policy looses potency as markets become more competitive. Although we consider a relative price elasticity of product demand of 2.0 to be a reasonable upper limit, if competition were to become much fiercer, for example because of government policies that dramatically

\footnotetext{
${ }^{19}$ Holden (2005) analyzes the incentives that monetary union may create for national unions to increase wage coordination, which in our model means raising the effective magnitude of $\sigma$.

${ }^{20}$ Raw empirical data reported in OECD (2003) show large, monotonic responses of employment to product market liberalization between 1978 and 1998 in 21 countries.

${ }^{21}$ For extended analysis see Nickell (1999).
} 
reduced barriers to trade and market entry, ${ }^{22}$ monetary policy would become irrelevant to unemployment performance in rigid wage regimes, where otherwise it exerts great effects. Firms charging non-competitive prices would be driven to bankruptcy and labor would be reallocated to surviving producers, no matter what the wage inflation posture of the central bank. The ensuing uniformity of product prices would eliminate the wage wedge, thereby nullifying the incentive of unions to pursue wage policies exploiting a gap between the real consumption wage and the real product wage. At the perfect competition limit $\eta=\infty$, unemployment falls to $U=(1-\alpha) \gamma$ at all values of $\phi$.

Figure 4 graphs simulations of the unemployment effects of variations in the weight unions attach to real wage premiums. $\gamma$ is a parameter that distorts competitive outcomes in labor markets, in that it represents the willingness of unions to impose wage levels exceeding the underlying productivity of the (given) labor force, thus driving unemployment above the perfect competition equilibrium $U=0 .^{23}$ An important message of Figure 4 is that unemployment outcomes are very sensitive to union real wage objectives. Across plausible settings for $\gamma$, which in our simulations imply union real wage goals that range from 7.5 to 17.5 percentage points above the market clearing level, equilibrium unemployment rates shift by as much as 7 percentage points.

$\gamma$ is directly analogous to the status of $\eta$ in product markets, and it interacts with monetary policy conservativeness in much the same fashion as $\eta \cdot{ }^{24}$ Hence monetary policy exerts greatest effects when union goals are most distorting - that is, at the larger values of $\gamma$. As $\gamma$ gets small, union wage behavior corresponds more on its own to competitive behavior and the conditioning effects of policy dissipate, just as is the case when the product price competition parameter $\eta$ gets large.

In principle $\gamma$ should be seen as a behavioral parameter, rather than a deep structural parameter like $\alpha$. Hence the relative weight unions' attach to real wages as opposed to unemployment in the determination of their nominal wage policies is subject to planned adjustment, although we make no attempt in this paper to model the internal dynamics of unions that might help explain revisions of their utility programs.

\footnotetext{
${ }^{22}$ See, for example, the analysis of Blanchard and Giavazzi (2003).

${ }^{23}$ Recall that productivity growth and the equilibrium rate of unemployment under pure competition are both normalized to zero in our model.

${ }^{24}$ Blanchard and Philippon (2003) analyze a model in which the union utility weight on the real wage level declines with union beliefs about the degree of product market competition. In our setting that would make $\gamma$ proportional to $\eta$, rather than being an independent parameter with separable effects.
} 


\section{Figure 4. The Effects of Monetary Policy Conservativeness on Unemployment by Variation in Union Real Wage Weights ${ }^{*}$}

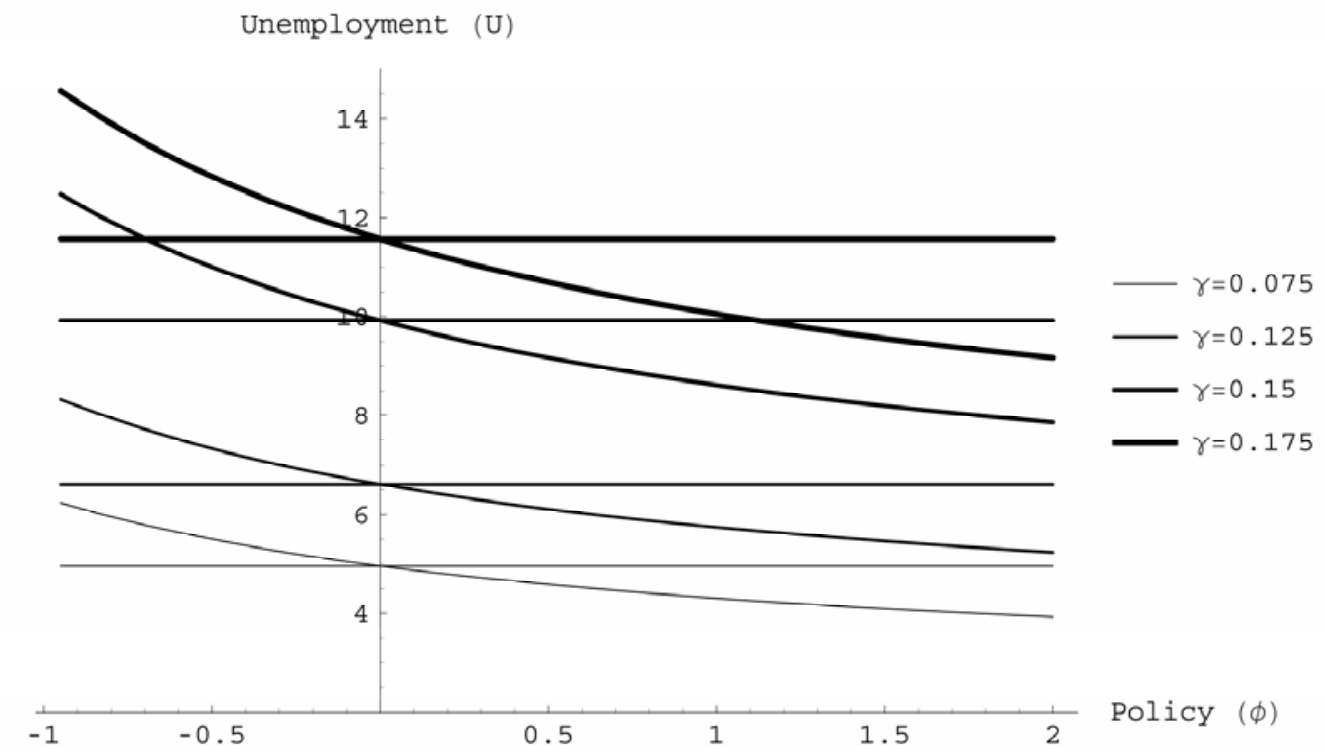

*Percentage point rates of unemployment are log approximations and were generated by parameter settings $\alpha=2 / 3, \sigma=0.4$ and $\eta=1.3$ as $\phi$ goes from its lower bound, -1 , to its upper limit, $\alpha /(1-\alpha)=2$ for various magnitudes of union real wage utility weights, $\gamma$. Rigid wage outcomes are depicted by the convex graph lines; flexible wage outcomes by the parallel lines.

\section{Summary and conclusions}

In this paper we applied a standard model of an economy with imperfectly competitive markets for goods and labor in which a central bank and several unions strategically interact. Unions set wages and firms set prices, subject to downward sloping labor and product demand functions. We used this workhorse model to investigate the macroeconomic consequences of monetary policy rules in two distinct labor market regimes: A rigid wage (“Stackelberg”) regime with binding contracts precluding nominal wages from being adjusted contemporaneously to variations of the money supply, and a flexible wage ("Nash”) regime where unions and the central bank simultaneously determine nominal wages and the money supply, respectively, in light of each other's best response policies.

If only one union is present in the labor market, or if product markets are perfectly competitive so that firms face a relative price elasticity of demand approaching infinity, neutrality holds no matter which wage formation regime is in place - systematic monetary policy affects inflation but not unemployment. However, in more realistic situations in which several unions are involved in wage setting and firms have at least some price setting market 
power, monetary policy has real effects in rigid wage regimes whenever the authorities employ a systematic policy rule. By contrast, in flexible wage regimes the monetary authority is unable to influence real variables. The real effects of monetary policy rules depend on wage setting institutions.

Our numerical results showed that conservative, restrictive monetary policies have great capacity to offset the potentially negative employment costs of decentralized bargaining when nominal wages are pre-committed and unions internalize systematic responses of the monetary authority to their wage setting behavior. Yet the very same internalization mechanism gives liberal, accommodating policies equally great capacity to aggravate unemployment arising from decentralized wage setting. In fact, at all combinations of wage setting centralization, product market competition, and the real wage orientation of union goals, liberal policies yield higher unemployment (and inflation) in a rigid wage labor markets than in flexible wage markets in which unions take the money supply as given. And, under plausible numerical settings of model parameters, the quantitative magnitudes were sizeable - generally amounting to several percentage points of unemployment. ${ }^{25}$

Finally, our results imply that conservative, anti-inflationary monetary policies always dominate liberal policies, in the sense that inflation is always lower and unemployment is never higher under restrictive policy as compared to liberal policy. Yet if monetary policy were compelled by law, social norms, or some other reason to accommodate rising wages and prices, then macroeconomic performance would be enhanced by a flexible wage labor market in which unions had the institutional capacity to adjust wages continuously to realizations of the money supply. In this respect a flexible wage labor market without binding contracts is more compatible with monetary policies that systematically accommodate nominal wage expansions.

\footnotetext{
${ }^{25}$ Our model implies that the effects of monetary policy in mixed systems - economies in which some wages are flexible and others are rigid and/or economies in which firms are endowed with quite different degrees of pricing power - are just weighted averages of outcomes of the sort depicted in Figures 1-4 - with weights equal to the shares contributed by wages set in various institutional configurations to the average, economy-wide wage. Waller (1992) focuses explicitly on a multi-sector economy. He analyzes monetary policy effects in an economy composed of a flexible wage ('classical') sector and a rigid wage ('nonclassical') sector that are endogenously connected via relative price effects.
} 


\section{Appendix: The workhorse monopolistic competition model}

The appendix gives some additional details about the economic model used in the main text. The demand for firm ij's product depends on its relative price and aggregate demand

(A.1) $\quad Y_{i j}^{d}=\left(\frac{P_{i j}}{P}\right)^{-\eta} \frac{M}{P}$

where $P_{i j}$ and $P$ are individual firm prices and the general price level, respectively. Firms are assumed distributed such that the general price level $P$ is a geometric average of individual firm prices $P_{i j} . \eta>1$ is the relative price elasticity of product demand faced by each firm, and $\left(\frac{M}{P}\right)$ is the aggregate quantity of real money. With lower case letters denoting logs, the foregoing imply that log aggregate demand is just $y^{d}=(m-p)$.

Each firm's uses a production technology (with secular technological progress fixed at 1.0) employing labor inputs only that exhibit decreasing returns to scale
(A.2) $\quad Y_{i j}=L_{i j}^{\alpha}$
$\alpha \in(0,1)$

where $Y_{i j}$ and $L_{i j}$ are the output supply and the labor input of firm $i j$. The production function implies that the labor requirement for any level of output is $L_{i j}=Y_{i j}^{1 / \alpha}$.

Firms maximize the real profit function

(A.3) $\Pi_{i j}=\frac{P_{i j}}{P} Y_{i j}^{d}-\frac{W_{i}}{P} L_{i j}$.

The usual profit maximization condition that marginal revenue equals marginal cost may thus be written

(A.4) $\frac{P_{i j}}{P}\left[1-\frac{1}{\eta}\right]=\frac{W_{i}}{P} \frac{1}{\alpha} Y_{i j}^{\frac{1-\alpha}{\alpha}}$.

By substituting (A.1) into (A.4), we obtain the optimal relative price of firm $i j$ as

(A.5) $\frac{P_{i j}}{P}=\left(\frac{\mu}{\alpha} \frac{W_{i}}{P}\right)^{\frac{\alpha}{\alpha+\eta(1-\alpha)}}\left(\frac{M}{P}\right)^{\frac{1-\alpha}{\alpha+\eta(1-\alpha)}}$ 
where $\mu=\left(1-\frac{1}{\eta}\right)^{-1}>1$ is the mark-up. Equation (A.5) states that the optimal relative price of firm ij rises with the real consumption wage of the firm's workers and with aggregate real money balances.

Equating (A.1) to (A.2) giving $\left(\frac{P_{i j}}{P}\right)^{-\eta} \frac{M}{P}=L_{i j}^{\alpha}$ and using (A.5) we can derive the following expression for employment in firm ij

$$
L_{i j}=\left(\frac{\mu}{\alpha} \frac{W_{i}}{P}\right)^{-\frac{\eta}{\alpha+\eta(1-\alpha)}}\left(\frac{M}{P}\right)^{\frac{1}{\alpha+\eta(1-\alpha)}}
$$

Taking logs of (A.6), we have firm ij's log labor demand as

(A.7) $\quad l_{i j}^{d}=\frac{m-p-\eta\left(w_{i}-p\right)}{\alpha+\eta(1-\alpha)}-\eta l_{0}$

where $l_{0}=\frac{\ln (\mu)-\ln (\alpha)}{\alpha+\eta(1-\alpha)}$ is a location parameter that henceforth we neglect. Log relative price from (A.5) is therefore

$$
p_{i j}-p=\frac{(1-\alpha)(m-p)+\alpha\left(w_{i}-p\right)}{\alpha+\eta(1-\alpha)}
$$

The conventional definition of the unemployment rate, $U=\frac{\left(L^{S}-L^{D}\right)}{L^{S}}$, is closely approximated by the difference of log labor supply and log labor demand, $l^{s}-l^{d}$. Using (A.7) the unemployment rate $U$ can be written

(A.9) $U_{i j}=\bar{l}_{i j}-\frac{m-p-\eta\left(w_{i}-p\right)}{\alpha+\eta(1-\alpha)}$

where $\bar{l}_{i j}$ is log labor supply to firm $i j$. For simplicity we treat $\bar{l}_{i j}$ parametrically and normalize it to zero. The unemployment rate is therefore proportional to $-l_{i j}^{d}$, which corresponds to equation (5) in the main text. Note that omitting $\bar{l}_{i j}$ and $l_{0}$ do not affect solutions for optimal programs because of the linear-quadratic functional forms of the objective functions (a proof is available by request), so these parameters y may be omitted without loss of generality. 
Averaging (A.8) over firms and rearranging, we obtain the reduced form for the equilibrium general price level as

(A.10) $p=\alpha w+(1-\alpha) m$

which in view of (A.2) and (A.7) implies that equilibrium log aggregate output is

(A.11) $y=\alpha(m-w)$.

Equilibrium aggregate unemployment (the negative of log aggregate labor demand) follows by taking the average of (A.9) and substituting for the log aggregate price level given by (A.10):

(A.12) $U=(w-m)$.

\section{References}

Acocella, N. and Di Bartolomeo G. (2004), "Non-neutrality of monetary policy in policy games,” European Journal of Political Economy, 20: 695-707.

Alesina, A. and Summers, L. (1993), "Central bank independence and macroeconomic performance: Some comparative evidence,” Journal of Money, Credit, and Banking, 25: 151163.

Barro, R.J. and Gordon D.B. (1983), "A positive theory of monetary policy in a natural rate model,” Journal of Political Economy, 91: 589-610.

Blanchard, O.J. and Giavazzi, F. (2003), "Macroeconomic effects of regulation and deregulation in goods and labor markets," Quarterly Journal of Economics, August, 879-907.

Blanchard, O.J. and Philippon, T. (2003), The decline of rents and the rise and fall of European unemployment,” MIT, mimeo.

Bleaney, M. (1996), “Central bank independence, wage-bargaining structure, and macroeconomic performance in OECD countries’, Oxford Economic Papers, 48, 20-38.

Bratsiotis, G. and Martin, C. (1999), ”Stabilization, Policy Targets and Unemployment in Imperfectly Competitive Economies,” Scandinavian Journal of Economics, 101, 241-256.

Canzoneri, M.B. (1985), "Monetary policy Games and the Role of Private Information," American Economic Review, 75(5): 1056-1070.

Coricelli, F., Cukierman A., and Dalmazzo A. (2005), "Monetary institutions, monopolistic competition, unionized labor markets and economic performance," forthcoming in Scandinavian Journal of Economics.

Coricelli, F., Cukierman A., and Dalmazzo A. (2004), "Economic performance and stabilization policy in a monetary union with imperfect labor and goods markets," in: Sinn H.W., M. Widgren and M. Kothenburger (eds.), European Monetary Integration, MIT Press, Cambridge MA, 3-40.

Cukierman, A. (2004), "Monetary institutions, monetary union and unionized labor markets Some recent developments," in Beetsma, R., Favero, C., Missale, A., Muscatelli, V.A., Natale, P. and Tirelli, P. (eds.), Monetary policy, fiscal policies and labour markets: Key 
aspects of macroeconomic policymaking in EMU, Cambridge University Press, Cambridge UK.

Cukierman, A. and Lippi F. (1999), "Central bank interdependence, centralization of wage bargaining, inflation and unemployment - Theory and evidence," European Economic Review, 43: 1395-1434.

Cukierman, A. and Lippi F. (2001), "Labour markets and monetary union: a strategic analysis,” The Economic Journal, 111: 541-561.

Douven, R.C.M.H. (2002), “Equilibrium rates and wage flexibility in Europe,” European Network of Economic Policy Research Institutes, Working Paper No. 10.

Eijffinger, S., Schaling, E. and Hoeberichts M. (1998), "Central bank independence: A sensitivity analysis,” European Journal of Political Economy, 14:73-88.

Fischer, S. (1977), "Long-term contracts, rational expectations, and optimal money supply rule,” Journal of Political Economy, 85: 191-206.

Fischer, S. and Summers L. (1989), "Should governments learn to live with inflation?," American Economic Review, 83: 382-387.

Franzese, R.J. (2001a), "Monetary policy and wage/price bargaining: Macro-institutional interactions in traded, public, and sheltered sectors," in Hall, P. and Soskice, D. (eds.) Varieties of Capitalism: The Institutional Foundations of Comparative Advantage. Oxford Univeristy Press.

Franzese, R.J. (2001b), "Strategic interactions of monetary policymakers and wage/price bargainers: A review with implications for the European Common-Currency Area," Empirica, 28: 457-486.

Franzese, R.J. (2002), Macroeconomic policies of developed democracies. Cambridge University Press.

Golden, M. Lange, P. and Wallerstein, M. (2002), "Union centralization among advanced industrial societies: An empirical study.” Dataset at http://www.shelley.polisci.ucla.edu/data.

Gordi, J. (1995), “Product diversity, endogenous markups and development traps,” Journal of Monetary Economics, 36:39-63.

Grilli, V., Masciandaro, D. and Tabellini, G. (1991), "Political and monetary institutions and public financial policies in the industrial countries,” Economic Policy, 13: 341-392.

Gylfason, T. and Lindbeck A. (1994), “The interaction of monetary policy and wages,” Public Choice, 79: 33-46.

Hall, P. (1994) "Central bank independence and coordinated wage bargaining: Their interaction in Germany and Europe,” German Politics and Society, Autumn: 1-23.

Hall, P. and Franzese, R. (1998), "Mixed signals: Central bank independence, coordinated wage bargaining and European monetary union,” International Organization, 52:505-535.

Holden, S. (2005), "Monetary regimes and the co-ordination of wage setting," European Economic Review, 49: 833-843

Iversen, T. (1999) Contested Economic Institutions: The Politics of Macroeconomics and Wage Bargaining in Advanced Democracies, Cambridge University Press, Cambridge UK.

Kydland, F.W. and Prescott E.C. (1977), "Rules rather than discretion: The inconsistency of optimal plans,” Journal of Political Economy, 85: 473-491. 
Lippi, F. (2003), "Strategic monetary policy with non-atomistic wage setters," Review of Economic Studies, 70: 1-11.

Logeay, C. and Tober, S. (2003), “Time-varying Nairu and real interest rates in the Euro area,” European Network of Economic Policy Research Institutes, Working Paper No. 24.

Ljungqvist, L. and Sargent T.J. (2000), Recursive macroeconomic theory, MIT Press, Cambridge MA.

Nickell, S. (1999), “Product markets and labour markets,” Labour Economics, 6:1-20.

OECD (2003), "Product market competition and economic performance,” Economic Outlook, 72:chapter 6.

Patinkin, D. (1956), Money, interest and prices, Harper\&Row, New York.

Rogoff, K. (1985), “The optimal degree of commitment to an intermediate monetary target," Quarterly Journal of Economics, 100: 1169-1189.

Soskice, D. and Iversen T. (1998), "Multiple wage-bargaining systems in a single European currency area," Oxford Review of Economic Policy, 14: 110-124.

Soskice, D. and Iversen T. (2000), “The non neutrality of monetary policy with large price or wage setters,” Quarterly Journal of Economics, 115: 265-284.

Waller C.J, (1992). “The choice of a conservative central banker in a multi-sector economy,” American Economic Review, 82: 1006-1012.

Waller C.J. and VanHoose, D.D (1992) "Discretionary monetary policy and socially efficient wage indexation,” Quarterly Journal of Economics, 107: 1451- 1460.

VanHoose, D.D. and Waller C.J, (1989). "Islands, indexation and monetary policy," Economic Inquiry, 27: 705-717. 